\title{
Mulheres e o abandono da figura paterna: considerações teórico-clínicas a partir da psicologia analítica
}

\author{
Women and the abandonment of the father figure: \\ theoretical and clinical considerations \\ based on analytical psychology
}

Antonio Paulo Pinheiro LIMA

\section{Resumo}

Este trabalho busca demonstrar, a partir de vinhetas clínicas, as consequências negativas trazidas na vida de mulheres pela experiência de terem sido abandonadas pela figura paterna. Neste estudo, o referencial teórico foi principalmente a psicologia analítica, além dos conceitos psicanalíticos de compulsão à repetição e melancolia. São também descritos os progressos alcançados no atendimento dos casos a partir da atuação psicoterapêutica baseada no método clínico junguiano. As conquistas obtidas, em termos gerais, dizem respeito a maior integração psíquica por parte dessas mulheres, que conseguiram estabelecer maior equilíbrio interno entre as polaridades masculina e feminina. Esse equilíbrio trouxe impactos positivos para elas, como melhora da autoestima e maior sentimento de autoconfiança, além de capacitá-las para o estabelecimento de relações afetivas mais saudáveis e menos calcadas em submissão e dependência.

Unitermos: Abandono. Individuação. Mulheres. Psicoterapia analítica. Relação pai-filho.

\begin{abstract}
The article seeks to demonstrate, by means of clinical vignettes, the negative consequences brought into women's lives by experiences of having been abandoned by the father figure. In this study, the theoretical benchmark was primarily Analytical Psychology, in addition to the psychoanalytic concepts of repetition compulsion and melancholy. There is also a description of the results achieved in cases treated with psychotherapy based on Jungian clinical method. The achievements, in general, relate to greater psychic integration by these women, who were able to establish greater internal balance between the masculine and feminine polarities. That balance brought positive impacts to these women, such as improved self-esteem and greater sense of confidence, and made possible for them to experience healthier emotional relationships, based on a lower degree of submission and dependence.
\end{abstract}

Uniterms: Abandonment. Individuation. Women. Analytical psychotherapy. Father-child relations.

A partir de estudos e da prática clínica como psiquiatra e psicoterapeuta, C. G. Jung desenvolveu a teoria de que as mulheres possuem em sua personalidade uma contraparte masculina, denominada

$\nabla \nabla \nabla \nabla \nabla$

1 Universidade de Brasília, Instituto de Psicologia, Programa de Pós-Graduação em Psicologia Clínica e Cultura, Departamento de Psicologia Clínica. SQN 313 , Bloco D, Ap. 401, Asa Norte, 70766040, Brasília, DF, Brasil. E-mail: <antonio.pinheiro.lima@gmail.com>. 
Animus."O Animus é uma espécie de sedimento de todas as experiências ancestrais da mulher em relação ao homem" (Jung, 1928/1978a, p.199). Essa contraparte masculina constitui uma compensação inconsciente da atitude feminina consciente, agindo, desse modo, como intermediário entre o Eu consciente da mulher e o seu inconsciente (Jung, 1912/1978b, 1961/2006; Pieri, 2002; Sanford, 2004; Stein, 2004).

A convivência com a figura paterna é o alicerce que permite o desenvolvimento dos conteúdos arquetípicos do Animus na mulher. A falta de oportunidade para o desenvolvimento do Animus faz com que ele permaneça indiferenciado, inconsciente, o que aumenta significativamente a probabilidade de que ele seja projetado (Jung, 1928/1978b, 1921/2003; Sanford, 2004).

Embora ainda haja carência de estudos no contexto brasileiro sobre a influência paterna no desenvolvimento infantil (Cia, Williams \& Aiello, 2005), é possível encontrar trabalhos que identificam os impactos negativos advindos de más experiências com a figura paterna, como discutem alguns trabalhos. Figuras paternas que praticam atos de negligência, omissão, ausência, autoritarismo, abuso e outras formas de violência tendem a incutir em suas filhas mulheres sentimentos de menos-valia, insegurança, baixa autoestima e dificuldade de estabelecer relacionamentos amorosos satisfatórios (Eizirik \& Bergmann, 2004; Pereira \& Silva, 2006; Costa, Legnani \& Zuim, 2009). A influência da figura paterna também se manifesta nas seguintes dimensões da vida dos filhos: competência social (Custódio \& Cruz, 2008); conflito com a lei (Dell'Aglio, Santos \& Borges, 2004); vulnerabilidade social e delinquência juvenil (Feijó \& Assis, 2004; Conceição \& Sudbrack, 2004); representações sobre parentalidade e relações de gênero (Perucchi \& Beirão, 2007); visão sobre o conceito de família e expectativas em relação à constituição de suas próprias famílias no futuro (De Antoni \& Koller, 2000); equilíbrio no processo de desenvolvimento (Gomes \& Resende, 2004); desempenho acadêmico (Cia, D’Affonseca \& Barham, 2004); trajetória vocacional (Gonçalves \& Coimbra, 2007); distúrbios alimentares (Gaspar, 2005; Nodin \& Leal, 2005).

Em sua prática clínica, o autor deste estudo percebe com frequência que as mulheres que vivenciam a experiência de terem sido abandonadas pela figura 822 paterna muitas vezes se engajam em relacionamentos amorosos que parecem ter a função de preencher as lacunas afetivas deixadas pelos pais ausentes. Desse modo, as mulheres parecem depositar nos parceiros amorosos todas as frustrações e expectativas de resgate do abandono imposto pela figura paterna na infância. Nesse contexto, é praticamente inviável um relacionamento saudável e equilibrado, pois as mulheres se encontram em estado constante de submissão e dependência. O parceiro amoroso torna-se o Pai, figura indispensável e portadora do poder masculino, sem a qual a mulher se vê destituída de qualquer possibilidade de sobrevivência emocional, sentindo-se como uma criança absolutamente desamparada e solitária, lançada num mundo hostil. Todo o poder e capacidade de realização efetiva são transferidos ao parceiro amoroso, o qual se torna senhor da mulher (Sanford, 2004).

Em muitos casos, os parceiros amorosos exercem abuso de poder, justamente por perceberem o estado de subserviência e dependência da mulher. Como todo relacionamento afetivo ocorre dentro de uma dinâmica em que há responsabilidade de todos os envolvidos, muitas vezes a própria mulher contribui para esse abuso, quando, numa postura de submissão e carência, torna-se "pegajosa", dependente e acaba por incitar no parceiro atitudes de domínio, afastamento, negligência, opressão e desrespeito. Essa dinâmica (mulher indefesa e carente e homem dominador e negligente) reedita a história da menina abandonada pela figura paterna. Tal reedição pode ser bem compreendida pelo conceito psicanalítico de compulsão à repetição e pela teoria junguiana dos complexos. Propõe-se, a seguir, uma breve descrição e articulação dos conceitos.

A compulsão à repetição é o mecanismo por meio do qual o inconsciente tende a buscar situações que possibilitem ao indivíduo reviver situações que foram geradoras de conflito e sofrimento psíquico (Freud, 1914/1979d, 1914/1979e, 1920/1979a, 1926/1979b). É como se o inconsciente estivesse à procura de situações análogas às que formaram o núcleo patogênico, numa tentativa de curar a ferida psíquica. É uma reedição de dinâmicas relacionais nocivas e/ou insatisfatórias, com o intuito de pavimentar os buracos deixados por vivências de traumas afetivos: "... o que permaneceu incompreendido retorna; como uma alma penada, não tem repouso até que seja encontrada solução e alívio" (Laplanche \& Pontalis, 1999, p.84). 
O conceito psicanalítico de compulsão à repetição pode ser articulado com a teoria junguiana sobre os complexos, os quais seriam conjuntos de ideias que se mantêm unidas por meio de um componente afetivo compartilhado. Essa teoria foi formulada pela escola de Zurique (Bleuler, Jung) a partir de experimentos com associação de palavras, os quais conferiram notoriedade internacional a Jung e o aproximaram de Freud, pois era uma espécie de "descoberta laboratorial"do inconsciente. As falhas de associação no experimento poderiam ser explicadas pela ação do recalque (Pereira, 2010).

Considerando-se que os temas que formam os complexos se aglutinam por critérios de ordem afetiva, e que esse afeto procura meios de descarga, pode-se aqui reforçar a pertinência de sua articulação com a compulsão à repetição. Com vistas à descarga afetiva, o complexo age de forma autônoma em relação às intenções conscientes do Eu e exerce sobre o sujeito - de forma compulsiva e repetitiva -, um poder de atração para situações que permitiriam reviver e "curar" a ferida emocional. A possibilidade de "cura" dá-se justamente porque existe um componente emocional compartilhado entre a situação atual e a vivência que originalmente provocou a ferida. Ou seja, ambas estão enredadas no mesmo complexo. Dessa forma, solucionar um conflito atual teria um impacto terapêutico sobre o complexo como um todo e, consequentemente, sobre todas as representações psíquicas que o compõem. Nos casos analisados neste artigo, a situação traumática seria a experiência do abandono da figura paterna, e os fracassos repetitivos na vida amorosa seriam as tentativas inconscientes atuais de reviver a ferida e curá-la.

A partir de considerações teórico-clínicas sobre o processo psicoterapêutico de quatro mulheres, o presente estudo busca explorar: a) os impactos causados em mulheres pela experiência de terem sido abandonadas pela figura paterna; b) as influências terapêuticas promovidas nesses impactos, a partir do processo de psicoterapia baseado na psicologia analítica.

\section{Método}

O presente estudo foi realizado a partir de processos psicoterápicos conduzidos pelo autor, em consultório particular. São estudos de caso situados no campo da metodologia clínico-qualitativa (Turato, 2000). Essa metodologia caracteriza-se, em linhas gerais, por considerar o fenômeno em seu setting natural, valorizando os sentidos e os significados que os sujeitos produzem acerca de si mesmos, pela postura existencialista do pesquisador e pelo caráter interpretativo de suas conclusões. Nesse item, são feitas considerações sobre coleta, registro, armazenamento e análise dos dados, bem como sobre o enquadre psicoterapêutico empregado nos atendimentos clínicos e os aspectos éticos envolvidos.

Os dados aqui analisados são fruto de observação clínica de vivências subjetivas de quatro mulheres ao longo do processo de psicoterapia. Não foi usado nenhum recurso tecnológico além dos registros por escrito ao final de cada sessão. A análise de sonhos também forneceu elementos importantes para ampliar a compreensão sobre os casos.

\section{Registro e armazenamento dos dados}

Seguindo os preceitos da Resolução 001/2009 do Conselho Federal de Psicologia (que dispõe sobre a obrigatoriedade de registro documental decorrente da prestação de serviços psicológicos), os dados oriundos da observação clínica foram registrados em documentos eletrônicos, confeccionados em programa de edição de textos. Esses documentos estão protegidos por senha. Os registros incluem identificação da paciente, avaliação da demanda inicial, relato das sessões e dados sobre encerramento e encaminhamento.

Nos relatos das sessões, redigidos imediatamente após cada consulta, costuma-se registrar frases consideradas emblemáticas por traduzirem o estado em que se encontram as pacientes e a evolução de suas histórias; as frases em itálico, inseridas abaixo no item "descrição dos casos", são oriundas desses registros específicos. São também incluídos dados de transferência/contratransferência e demais impressões subjetivas do analista. A ideia é registrar com o máximo de detalhes possível os elementos que compõem a relação terapêutica, incluindo sentimentos, reações, falas significativas etc.

A matéria-prima para a análise foram os registros escritos dos atendimentos. O referencial teórico para 
análise dos dados foi, principalmente, a psicologia analítica, com textos clássicos de Jung e de outros autores mais recentes. Contou-se também com o aporte da psicanálise para compreender especificamente os mecanismos da compulsão à repetição e da melancolia.

\section{Enquadre psicoterapêutico}

Conforme mencionado acima, todos os atendimentos foram realizados pelo autor deste artigo, em consultório particular. O consultório atende a todas as recomendações do Conselho Federal de Psicologia referentes a conforto e segurança. As terapias foram individuais, com duração total dos processos variando entre 4 meses e 2 anos. As sessões eram semanais, de 50 minutos aproximadamente. Nos momentos de maior crise e sofrimento, o intervalo entre as sessões foi abreviado, passando a haver dois atendimentos por semana. Nesses momentos, havia uma modificação no manejo clínico, e o trabalho assumia contornos de terapia de suporte. Passado o momento mais crítico, a psicoterapia reassumia seu formato normal.

A postura clínica adotada nos atendimentos dos casos foi inspirada no método clínico da psicologia analítica, o qual se caracteriza por ser dialético e sintético (Jung, 1946/1988b). Dialético por priorizar um tipo de relação mais horizontal, com abertura para que o paciente traga para o encontro terapêutico as suas próprias percepções, construindo sentido sobre si mesmo. Sintético por adotar uma teoria progressiva sobre a psique, percebendo as manifestações do inconsciente não apenas como rastros de psicopatologia, mas como movimentos em direção à plenitude e à realização pessoal. Vejam-se com mais detalhes esses conceitos.

Jung afirmou: "Só aquilo que somos realmente tem o poder de curar-nos."(Jung, 1928/1978a, p.155). Ao reconhecer que o paciente é o verdadeiro detentor do elixir cura, Jung reconfigurou o papel do analista em seu método: se antes Ihe cabia ocupar o lugar inabalável de sujeito-suposto-saber e decifrar para o paciente as manifestações inconscientes que ele produzia, agora o analista passa a estabelecer uma relação dialética, colocando em suspenso seus pressupostos e construindo, em parceria com o paciente, a compreensão das expressões simbólicas do inconsciente. (Fordham, 1969/2002).
"O sistema dele se relaciona com o meu, pelo que se produz um efeito dentro do meu próprio sistema. Este efeito é a única coisa que posso oferecer ao meu paciente individual e legitimamente" (Jung, 1935/1988a, p.3).

O método clínico da psicologia analítica também pressupõe que existe uma função teleológica ou progressiva para as manifestações inconscientes, ou seja, nem tudo que provém do inconsciente é causado por um complexo ou núcleo patogênico. Jung considerava que certas manifestações inconscientes, tais como sonhos e sintomas, podem consistir numa expressão autônoma e independente do inconsciente, e não necessariamente uma reação patológica ou de regressão a estágios infantis (Jung, 1935/1988a).

Ao reconhecer a tendência progressiva da psique, Jung propõe que o inconsciente busca se manifestar e atingir a autorrealização, agindo de forma autônoma, para além da consciência e da voluntariedade. Essa classe de manifestações não poderiam ser classificadas, portanto, como sintomas de uma doença, mas, sim, como expressões naturais de um inconsciente que almeja a autorrealização e o desenvolvimento da totalidade originária. A esse processo de autorrealização, de contato com a própria subjetividade, de reconhecimento e abertura para manifestação das inclinações ontológicas de cada um, Jung deu o nome de individuação (Edinger, 2005; Hall, 1988; Jung, 1928/1984, 1939/ 2002a, 1940/2002b; Pieri, 2002; Stein, 2004; von Franz, 2004).

Pode-se dizer, portanto, que o método dialético-sintético de Jung aproxima-se da corrente de pensamento humanista, pois qualifica e estimula a capacidade do indivíduo de produzir sentido sobre si mesmo. Analista e paciente são coautores da mesma obra, qual seja, a cura mediante a ressignificação do conflito, numa interação compartilhada entre dois seres humanos que firmaram uma aliança de trabalho e traçaram uma meta comum. O analista contribui para o processo colocando-se como interlocutor, qualificando a fala do sujeito e criando espaço para que surjam novos caminhos para a abordagem das questões (Zinkin, 1969/2002). Ele também se oferece, como pessoa, em sacro ofício, para ser envolvido na teia da relação transferencial, que também serve como veículo para a atualização de con- 
teúdos inconscientes e para a promoção de um contato do indivíduo com temas que, de outro modo, seriam inacessíveis (Jung, 1946/1988b; Stein \& Schwartz-Salant, 2000).

Levando-se em consideração esses pressupostos, foi adotada nos atendimentos aqui mencionados uma postura clínica baseada na ampliação de consciência sobre a relação das pacientes com a figura paterna. $\mathrm{O}$ processo conduziu à elaboração dos seguintes aspectos: atitude que a paciente assumia no mundo (inibição versus proatividade); maneira como cada paciente percebia a si própria (autoimagem) e ao outro (idealização versus desvalorização); maneira como a paciente se posicionava nos relacionamentos afetivos (autonomia versus dependência). Foi estabelecida, no processo de psicoterapia, uma relação humana pautada no cuidado e na ampliação de consciência, com vistas a identificar e reparar as lacunas deixadas por traumas afetivos ligados às experiências de abandono da figura paterna (Stein \& Schwartz-Salant, 2000).

Há na literatura outros estudos que trabalham a questão do feminino a partir do método da psicologia analítica (Zweig, 1994; Young-Eisendrath, 1995). Destaca-se, em particular, a tese de doutorado de Parisi (2009), que encontrou resultados semelhantes aos descritos neste artigo, em pesquisa com um grupo de mulheres que passaram pelo processo de separação amorosa. Para a autora, a individuação passa necessariamente por um processo de diferenciação e recolhimento das projeções depositadas no parceiro.

\section{Aspectos éticos}

As pacientes dos casos aqui descritos foram informadas sobre a possibilidade de utilização dos registros para estudos clínicos e autorizaram a divulgação dos dados mediante a garantia do anonimato. Assim, os nomes aqui apresentados são fictícios e os registros clínicos que subsidiaram o estudo estão mantidos em completa segurança e confidencialidade. Também foi oferecida às pacientes a possibilidade de acessar o material produzido a partir da análise dos casos. Dessa maneira, foram cuidadosamente atendidos todos os incisos do Artigo 16 do Código de Ética Profissional do Psicólogo, em que se regulamenta a realização de estu- dos, pesquisas e atividades voltadas para a produção de conhecimento em psicologia.

\section{Descrição dos casos}

\section{Caso 1: Patrícia}

\section{Descrição da experiência com a figura paterna}

Patrícia teve com o pai uma experiência de abandono, descaso, rejeição. Ele nunca a aceitou plenamente como filha. Por várias vezes, ela foi visitá-lo e ele simulava estar ausente, para não precisar recebê-la.

\section{Considerações teórico-clínicas}

Patrícia apresentava um quadro clínico com sintomas de ansiedade, instabilidade de humor, irritação e dificuldade de controlar os impulsos. Há um histórico de compulsão alimentar, promiscuidade sexual e envolvimento com drogas (mais acentuado na adolescência). Demonstrava incapacidade de se realizar profissionalmente, e é plausível pensar que isso estaria relacionado aos sentimentos de menos-valia e baixa autoestima. Patrícia não se percebia capaz de realizar as mudanças que desejava: partir para a iniciativa privada, ser empresária e dona do próprio negócio.

Patrícia frequentemente se queixava de carência afetiva e solidão amorosa. Existia a busca por um ideal de homem, a qual sempre terminava em frustração por traição ou abandono. Foi possível observar que ela se sentia atraída por homens narcisistas e individualistas, e que suas atitudes (carência demasiada, agressividade, desconfiança, ciúmes, desqualificação) a tornavam desagradável ao parceiro, que se desgastava e acabava reagindo com agressividade, afastamento ou rompimento. Essas atitudes eram recebidas por ela como uma confirmação da "profecia", fortemente vinculada à vivência com o pai, de que homens não prestam e vão maltratá-la ou abandoná-la a qualquer momento. Patrícia apresentava a autoimagem de que não tenho valor perante os homens, nenhum homem me quer para nada além de sexo. Ela percebia a figura masculina como traiçoeira, falsa e maléfica. Os homens de sua idade eram percebidos como fracos, inseguros e afeminados. Patrícia nutria a seguinte crença: "Acho que existe um ho- 
mem perfeito pra mim, mais velho, másculo, protetor, bem-sucedido, seguro, mas ele não chega...".

A partir dessas características, observou-se que, para Patrícia, o ideal de homem se confundia com o ideal de figura paterna. Porém, em ambas as situações como mulher e como filha -, esse ideal estava ausente. Ela tendia a justificar essa ausência ora pela maldade dos homens, ora por suas próprias imperfeições. Na primeira situação, ela era vítima do mal que há nos homens; na segunda, ela era rejeitada por ser cheia de defeitos. Com essas crenças sobre o outro e sobre si mesma, era difícil vislumbrar o estabelecimento de relações afetivas saudáveis e equilibradas.

\section{Caso 2: Sofia}

\section{Descrição da experiência com a figura paterna}

O pai abandonou a família e recusou-se a estabelecer vínculo afetivo estável com Sofia após se separar da mãe dela. Nunca mais procurou saber notícias da filha.

\section{Considerações teórico-clínicas}

No acompanhamento de Sofia, foram observados alguns indicadores de ansiedade e depressão, tais como humor rebaixado, baixa autoestima, angústia e dificuldade para dormir e se concentrar. Ela apresentava a seguinte autoimagem: Não tenho valor; só decepciono os outros, mereço morrer. A dinâmica de relacionamento com figuras internas e externas era permeada pela ambivalência: amor e ódio, submissão e revolta. Via as mulheres como fracas, e os homens como os detentores do poder. Nutria admiração, subserviência e inveja. Vingava-se do abandono e opressão, mas sentia culpa em seguida. Buscava independência, mas tinha medo de perder o afeto.

A partir das falas de Sofia, observou-se que ela possuía uma percepção conflituosa sobre a figura masculina: Homens detêm poder sobre mim. São superiores a mim. Homens usam e abusam de mim de acordo com a conveniência deles. Eu os quero, mas tenho inveja do seu poder raiva porme sentir usada. Querovingança, mas ao mesmo tempo, preciso deles para que me salvem da minha miséria. Após a vingança, a fantasia que emergia era:
Sou uma aproveitadora, que engana os homens. Não presto, não tenho valor, sou uma ordinária.

Dessa forma, percebe-se que as figuras masculinas a feriam duplamente: primeiro pela rejeição e descaso, depois por lhe causarem sentimentos de culpa. Sabe-se que o mecanismo da culpa está intimamente ligado à depressão. É clássica a definição de Freud para a melancolia:"a sombra do objeto perdido recai sobre o Eu", ou seja, a raiva que ela sentia do ex-namorado voltava-se contra ela própria ao final do relacionamento, dando início a um processo de autofustigamento do Eu (Freud, 1917/1979c).

Assim como no caso de Patrícia, descrito acima, é possível perceber no caso de Sofia a fusão que existia entre os ideais de homem e de pai. Ela se sentia atraída por homens com as seguintes características: "Gosto de homens grisalhos que usam aliança!" Ela relatou um sonho no qual aparecia um homem descrito como uma mistura entre o pai e o ex-namorado. O homem era acompanhado por uma cobra, sua aliada, que havia picado Sofia anteriormente. Essa figura masculina apareceu no sonho como distante de Sofia e de costas para ela. Uma possível interpretação para essa imagem é a relação de distanciamento que Sofia tinha com o Animus, o qual era projetado nos homens com quem se relacionava (Jung, 1921/2003). Partindo-se desse pressuposto, a dependência afetiva estaria relacionada à dificuldade de Sofia de reconhecer o aspecto masculino em si mesma. Essa dificuldade pode ser considerada como um impacto da ausência da figura paterna no momento da constituição de Sofia como pessoa.

\section{Caso 3: Valquíria}

\section{Descrição da experiência com a figura paterna}

Valquíria teve uma experiência de abandono na infância. O pai trocou a família pela militância política e, pouco tempo depois, faleceu.

\section{Considerações teórico-clínicas}

Valquíria apresentava indicadores de depressão, tais como humor rebaixado e baixa autoestima. Pouco antes de ingressar na psicoterapia relatada neste artigo, passou por um severo episódio de síndrome do pânico, 
com fortes características persecutórias. Nos relacionamentos interpessoais, era submissa e tinha muita dificuldade para se colocar de maneira assertiva. Novamente pode-se pensar no impacto negativo da ausência paterna no desenvolvimento da relação com o Animus. A contraparte masculina da personalidade era percebida como ausente. Frequentemente se via envolvida em relacionamentos afetivos desequilibrados, nos quais colocava a si própria em situação de dependência afetiva dos companheiros. Assim como nos dois casos anteriores, a atração sexual se dava por homens cujas características poderiam ser facilmente associadas à figura paterna - homens mais velhos e dominadores, figuras de autoridade.

Valquíria possuía a seguinte autoimagem: "Sou fraca, confusa, dependente, incapaz, desinteressante". Ela percebia os homens assim:

"Homens são perigosos, mas também são necessários para o meu equilíbrio. Sem eles, me sinto só, fraca, impotente. Eles me têm na mão e, se me abandonam, fico arruinada. Eles só me querem como uma aventura sem compromisso".

Aventa-se a hipótese de que a opção do pai pelo engajamento político e consequente ausência no lar fez com que Valquíria se sentisse incapaz de reter o interesse dele. Não se sentiu objeto de desejo e atribuiu a si mesma a culpa por isso. Esse sentimento poderia ajudar a compreender sua tendência repetitiva para se envolver com homens que possuíssem características paternas marcantes e se submeter a eles, como se detivessem poder absoluto sobre sua vida.

Fazendo uso do aporte teórico da psicanálise, pode-se pensar numa compulsão à repetição por ser iludida, passada para trás, trocada, desprezada. Todavia, é comum ocorrer uma nova frustração, pois, na realidade, o que se observa é um mecanismo semelhante ao das profecias autorrealizadoras: o indivíduo já inicia a relação intuindo que o desfecho será desfavorável, e essa postura acaba por desencadear o temido (porém antevisto) final trágico. Isso confirma a percepção original da pessoa, como se ela pudesse dizer: "Sabia que isso iria acontecer. Eu só atraio homens que não prestam. Os bons não se interessam pormim..." . No caso de Valquíria, essa percepção da dinâmica colocava-a numa posição de responsabilidade e culpa pelo fracasso, o que possivelmente estava na base do mecanismo da depressão, conforme a teoria psicanalítica da melancolia.

\section{Caso 4: Luísa}

\section{Descrição da experiência com a figura paterna}

O pai abandonou Luísa após divorciar-se da mãe da menina. Não fez qualquer esforço significativo para manter a convivência com a filha após encerrar o relacionamento conjugal. Luísa também viveu abuso sexual por parte do padrasto, sem que a mãe fizesse qualquer intervenção.

\section{Considerações teórico-clínicas}

Luísa apresentava um quadro de baixa autoestima, insegurança e desvalorização de si mesma. 0 sentimento de ter sido abandonada pela figura paterna após a separação conjugal dos pais abalou gravemente a convicção de Luísa sobre seu próprio valor e importância. A situação agravou-se com a negligência/conivência da mãe diante do abuso sexual do padrasto.

Essas vivências de Luísa contribuíram para que fosse construída a seguinte percepção sobre a figura masculina: "Não confio totalmente nos homens. Eles têm um lado bicho que não conseguem controlar. Só se interessam pelo meu corpo". Luísa formava com os homens vínculos de profunda dependência afetiva e financeira. Colocava-se em situações em que, sem o apoio masculino, seus projetos fracassavam.

Ela chegou a se prostituir durante um tempo, ocasião na qual afirmava ter conhecido o lado selvagem e traidor dos homens. Sentia repulsa e vergonha por ter vivido essa experiência e buscava, no relacionamento atual, viver um amor romântico e idealizado. Entrar em contato com a natureza animalesca dos homens gerava nela um profundo sentimento de desprezo, que de certo modo a colocava numa postura de superioridade. Todavia, internamente, Luísa também sentia que se degradava, o que provocava o sentimento de culpa e rejeição por si mesma.

\section{Mudanças obtidas e discussão}

Os quatro processos terapêuticos aqui mencionados já foram concluídos, com mudanças positivas em todos. Patrícia passou a se valorizar mais e, com isso, também conseguiu controlar melhor os impulsos 
autodestrutivos. Também reviu sua imagem sobre a figura masculina e passou a compreender melhor os mecanismos das relações afetivas, saindo da dicotomia vilão-vítima. Dessa forma, está mais preparada para viver relacionamentos saudáveis e com maior equilíbrio. Sofia aprendeu a se ver de forma mais independente, libertando-se da submissão diante do masculino e investindo em si mesma para realizar seus sonhos pessoais e profissionais. Valquíria superou a tendência a se infantilizar nas relações, e agora se sente em busca de um companheiro, e não de um pai. Também passou a adotar uma postura mais assertiva e deu grandes saltos profissionais, realizando um sonho antigo de conquistar um emprego bem remunerado e bom status social. Luísa obteve grande alívio ao poder confessar que se prostituiu durante uma fase de sua vida; a psicoterapia ajudou-a a compreender melhor esse processo e a se perdoar. A partir disso, melhorou a sua relação com os homens, emancipando-se da dependência financeira e libertando-se da busca de um ideal romântico. Esse aspecto trouxe melhor convívio com o namorado atual e maior satisfação no plano amoroso.

Veja-se agora, com mais profundidade, uma articulação entre as mudanças positivas conquistadas pelas pacientes e a psicoterapia baseada na psicologia analítica.

A condução clínica dos casos, baseada nos princípios de acolhimento e liberdade de expressão, permitiu, em primeiro lugar, que as pacientes realizassem uma catarse de sentimentos negativos em relação à figura paterna.

A relação transferencial foi importante nesse processo, pois serviu de veículo para que os conteúdos inconscientes fossem atualizados em análise. O manejo clínico da transferência, na perspectiva dialético-sintética, proporcionou às pacientes um contato restaurador com a figura masculina. O olhar cuidador do psicoterapeuta criou oportunidade para que as pacientes pudessem reconstruir o olhar sobre si mesmas, como alguém que possui valor intrínseco.

Mesmo numa relação dialética, em que se busca a renúncia de autoridade, a figura do analista é recoberta de projeções, como se ele ocupasse o lugar de suposto "polo saudável" da díade. Essa projeção, num primeiro momento, foi importante, porque forneceu às pacientes 828 elementos de identificação para que elas próprias pu- dessem desenvolver esse polo saudável em sua personalidade (von Franz, 2004). Tal desenvolvimento é possível quando o analista não comete abuso de poder (Guggenbuhl-Craig, 2004) e"devolve", por meio da interpretação, as projeções ao paciente, reconhecendo (e levando-o a reconhecer) que o fato de perceber a"saúde" no analista se dá justamente porque ele próprio possui esse núcleo potencialmente saudável (Steinberg, 1992).

Esse tipo de manejo dialético-sintético da transferência arquetípica do Animus permitiu às pacientes um contato saudável e restaurador com a figura masculina, o que não tinha sido possível até então em razão da experiência de abandono do pai e dos sucessivos fracassos nos relacionamentos amorosos (Lambert, 1973/2002; Stein \& Schwartz-Salant, 2000). A aproximação das pacientes com os conteúdos arquetípicos do Animus possibilitou-Ihes desenvolver maior segurança e autoestima, além de capacitá-las para o estabelecimento de relações afetivas mais saudáveis e menos calcadas em submissão e dependência.

\section{Considerações Finais}

Em síntese, o processo terapêutico foi palco para vivências de integração psíquica por parte dessas mulheres, que conseguiram estabelecer maior equilíbrio interno entre as polaridades masculina e feminina. Ao estabelecer uma relação mais saudável com o seu Animus - que ocupa um lugar intermediário entre o "Eu" consciente e o inconsciente coletivo - as mulheres também abriram caminho para uma aproximação com o arquétipo que Jung denominou de Si-mesmo. Esse arquétipo se refere à integração equilibrada dos pares de opostos na personalidade e ao desabrochar das potencialidades originárias da psique. Quanto mais fluida a relação entre o "Eu" e o Si-mesmo, mais o sujeito avança em seu processo de individuação, ou seja, no reconhecimento de quem se é verdadeiramente, para além das máscaras sociais.

O encontro terapêutico também tornou possível que as mulheres se libertassem da prisão de serem "destinadas ao infortúnio" por terem vivido experiências de abandono ou má relação com o pai. Enquanto a mulher culpar o pai por todas as mazelas em que se encontra, nada restará a fazer. É preciso que ela aprenda a curar as feridas e conviver com as cicatrizes, assumindo a responsabilidade. Sobre sua vida e buscando em si própria a 
força, o cuidado e a proteção que ressente não ter recebido da figura paterna. Em termos junguianos, trata-se de construir uma relação de maior integração com o Animus, abrindo caminho para o Si-mesmo e, consequentemente, para a individuação.

\section{Referências}

Cia, F., D’Affonseca, S. M., \& Barham, E. J. (2004). A relação entre o envolvimento paterno e o desempenho acadêmico dos filhos. Paidéia, 14 (29), 277-286.

Cia, F., Williams, L. C. A., \& Aiello, A. L. R. (2005). Influências paternas no desenvolvimento infantil: revisão da literatura. Psicologia Escolar e Educacional, 9 (2), 225-233.

Conceição, M. I. G., \& Sudbrack, M. F. O. (2004). Estudo Sociométrico de uma instituição alternativa para crianças e adolescentes em situação de rua: construindo uma proposta pedagógica. Psicologia: Reflexão e Crítica, 2004, 17 (2), 277-286.

Costa, L. F., Legnani, V. N., \& Zuim, C. B. Di B. (2009). A menina que se constituiu no contexto do tráfico: o estudo psicossocial forense e o resgate da função paterna. Fractal: Revista de Psicologia, 21 (1), 151-162. Recuperado em julho 30, 2010, disponível em <http://www.scielo. br>. doi: 10.1590/S1984-02922009000100012.

Custódio, S., \& Cruz, O. (2008). As representações mentais das crianças acerca das figuras parentais. Psicologia:Teoria e Pesquisa, 24 (4), 393-405.

De Antoni, C., \& Koller, S. H. (2000). A visão sobre família entre as adolescentes que sofreram violência intrafamiliar. Estudos de Psicologia (Natal), 5 (2), 347-381.

Dell'Aglio, D. D., Santos, S. S., \& Borges, J. L. (2004). Infração juvenil feminina: uma trajetória de abandonos. Interação em Psicologia, 8 (2), 191-198.

Eizirik, M., \& Bergmann, D. S. (2004). Ausência paterna e sua repercussão no desenvolvimento da criança e do adolescente: um relato de caso. Revista de Psiquiatria do Rio Grande do Sul, 26 (3), 330-336. Recuperado em julho 30, 2010, disponível em <http://www.scielo.br>. doi: 10.159 o/S0101-81082004000300010.

Edinger, E. F. (2005). Anatomia da psique. São Paulo: Cultrix.

Feijó, M. C. \& Assis, S. G., (2004). O contexto de exclusão social e de vulnerabilidades de jovens infratores e de suas famílias. Estudos de Psicologia (Natal), 9 (1), 157-166.

Fordham, M. (2002). Technique and counter-transference. In M. Fordham, R. Gordon, J. Hubback \& K. Lambert (Eds.), Technique in Jungian analysis. London: Karnac. (Original work published 1974).

Freud, S. (1979a). Além do princípio do prazer. In S. Freud. Obras psicológicas completas (Vol. 17). Rio de Janeiro: Imago. (Originalmente publicado em 1920).

Freud, S. (1979b). Inibição, sintoma e angústia. In S. Freud. Obras psicológicas completas (Vol. 20). Rio de Janeiro: Imago. (Originalmente publicado em 1926).
Freud, S. (1979c). Luto e melancolia. In S. Freud. Obras psicológicas completas (Vol. 14). Rio de Janeiro: Imago. (Originalmente publicado em 1917).

Freud, S. (1979d). Recordar, repetir, perlaborar. In S. Freud. Obras psicológicas completas (Vol. 12). Rio de Janeiro: Imago. (Originalmente publicado em 1914).

Freud, S. (1979e). Sobre o narcisismo: uma introdução. In S. Freud. Obras psicológicas completas (Vol. 14). Rio de Janeiro: Imago. (Originalmente publicado em 1914).

Gaspar, F. L., (2005). A violência do outro na anorexia: uma problemática de fronteiras. Revista Latinoamericana de Psicopatologia Fundamental, 8 (4), 629-643.

Gomes, A. J. S., \& Resende, V. R., (2004). O pai presente: o desvelar da paternidade em uma família contemporânea. Psicologia: Teoria e Pesquisa, 20 (2), 119-125.

Gonçalves, C. M., \& Coimbra, J. L. (2007). O papel dos pais na construção de trajectórias vocacionais dos seus filhos. Revista Brasileira de Orientação Profissional, 8 (1), 1-17.

Guggenbuhl-Craig, A. (2004). O abuso de poder na psicoterapia. São Paulo: Paulus.

Hall, J. A. (1988). A experiência junguiana. São Paulo: Cultrix.

Jung, C. G. (1978a). O eu e o inconsciente. In C. G. Jung. Obras completas (Vol. 7). Petrópolis: Vozes. (Originalmente publicado em 1928).

Jung, C. G. (1978b). Psicologia do inconsciente. In C. G. Jung. Obras completas (Vol. 7). Petrópolis: Vozes. (Originalmente publicado em 1912).

Jung, C. G. (1984). A energia psíquica. In C. G. Jung. Obras completas (Vol. 8). Petrópolis: Vozes. (Originalmente publicado em 1928).

Jung, C. G. (1988a). Princípios básicos da prática da psicoterapia. In C. G. Jung. Obras completas (Vol. 16). Petrópolis: Vozes. (Originalmente publicado em 1935).

Jung, C. G. (1988b). A psicologia da transferência. In C. G. Jung. Obras completas (Vol. 16). Petrópolis: Vozes. (Originalmente publicado em 1946).

Jung, C. G. (2002a). Consciência, inconsciente e individuação. In C. G. Jung. Obras completas (Vol. 9/1). Petrópolis: Vozes. (Originalmente publicado em 1939).

Jung, C. G. (2002b). A psicologia do arquétipo da criança. In C. G. Jung. Obras completas (Vol. 9/1). Petrópolis: Vozes. (Originalmente publicado em 1940).

Jung, C. G. (2003). Tipos psicológicos. In C. G. Jung. Obras Completas (Vol. 6). Petrópolis: Vozes. (Originalmente publicado em 1921).

Jung, C. G. (2006). Memórias, sonhos, reflexões. Rio de Janeiro: Nova Fronteira. (Originalmente publicado em 1961).

Lambert, K. (2002). The personality of the analyst in interpretation and therapy. In M. Fordham, R. Gordon, J. Hubback \& K. Lambert (Eds.), Technique in Jungian analysis. Londres: Karnac. (Original work published 1973).

Laplanche, J., \& Pontalis, J.-B. (1999). Vocabulário da psicanálise. São Paulo: Martins Fontes.

Nodin, N., \& Leal, I. (2005). Representações paternas na anorexia nervosa. Análise Psicológica, 2 (23), 201-208. 
Parisi, S. (2009). Separação amorosa e individuação feminina: uma abordagem em grupo de mulheres no enfoque da psicologia analítica. Tese de doutorado não-publicada, Programa de Pós-Graduação em Psicologia, Universidade de São Paulo.

Pereira, H. (2010). A psique como rede de complexos: o encontro de Jung com Tarde e Latour. In A. A. L. Ferreira, L. L. Freire, Moraes, M. \& R. J. J. Arendt (Orgs.), Teoria atorrede e psicologia (pp. 200-220). Rio de Janeiro: Nau.

Pereira, R. C., \& Silva, C. M. (2006). Nem só de pão vive o homem. Sociedade e Estado, 21 (3), 667-680. Recuperado em julho 30, 2010, disponível em <http://www.scielo. br>. doi: 10.1590/S0102-69922006000300006.

Perucchi, J., \& Beirão A. M., (2007). Novos arranjos familiares: paternidade, parentalidade e relações de gênero sob o olhar de mulheres chefes de família. Psicologia Clínica, 19 (2), 57-69.

Pieri, P. F. (2002). Dicionário Junguiano. São Paulo: Paulus.

Sanford, J. (2004). Os parceiros invisíveis. São Paulo: Paulus.

Stein, M. (2004). Jung, o mapa da alma. São Paulo: Cultrix.
Stein, M., \& Schwartz-Salant, N. (2000). Transferênciacontratransferência. São Paulo: Cultrix.

Steinberg, W. (1992). Aspectos clínicos da terapia junguiana. São Paulo: Cultrix.

Turato, E. R. (2000). Introdução à metodologia da pesquisa clínico-qualitativa: definição e principais características. Revista Portuguesa de Psicossomática, 2 (1), 93-108.

von Franz, M.-L. (2004). Psicoterapia. São Paulo: Paulus.

Young-Eisendrath, P. (1995). Bruxas e heróis: uma abordagem feminista na terapia junguiana de casais. São Paulo: Summus.

Zinkin, L. (2002). Flexibility in analytic technique. In M. Fordham, R. Gordon, J. Hubback \& K. Lambert (Eds.), Technique in Jungian analysis. London: Karnac.

Zweig, C. (Org.) (1994). Mulher: em busca da feminilidade perdida. São Paulo: Gente.

Recebido em: 22/3/2011

Versão final em: 27/2/2012

Aprovado em: 28/6/2012 